\title{
Revisões femorais de artroplastias totais do quadril com afrouxamentos assépticos e fraturas periprotéticas: análise de 49 casos tratados com haste de Wagner*
}

\author{
Femoral revision total hip arthroplasties with aseptic loosening and \\ periprosthetic fractures. Analysis of 49 cases treated with Wagner stem
}

\author{
Sergio Nogueira Drumond', Fernando Corradi Fonseca Drumond², \\ Bruno Kaehler de Albuqueroue Maranhão², Leonardo Corradi Rodrigues La Cruz ${ }^{2}$
}

\section{RESUMO}

Objetivo: Avaliar 49 quadris em 48 pacientes submetidos a revisão de artroplastia total do quadril usando a haste de Wagner. Métodos: De abril de 1999 a janeiro de 2005, foram tratados 49 quadris em pacientes portadores de afrouxamento femoral (39 quadris) ou fratura periprotética do fêmur (10 quadris) com revisão da artroplastia com a prótese de Wagner. $O$ seguimento médio foi de 35 meses e a média de idade, de 63,4 anos. As revisões do componente femoral foram realizadas em $\mathbf{4 9}$ quadris e, simultaneamente, no componente acetabular em 36 quadris. Resultados: A avaliação dos resultados pelo índice de D'Aubignè-Postel-Charnley apresentou melhora estatisticamente significante no pós-operatório em relação ao préoperatório $(\mathrm{p}<\mathbf{0 , 0 0 1 )}$. Os problemas mais importantes foram o alto índice de luxações (três quadris) e de luxações associadas a afundamento da haste (dois quadris). Os quatro resultados insatisfatórios deveram-se a afrouxamen-

* Trabalho realizado nos Serviços de Ortopedia e Traumatologia dos Hospitais Belo Horizonte e Ortopédico de Belo Horizonte (MG), Brasil.

1. Doutor, Professor Adjunto do Departamento de Ortopedia e Traumatologia da Faculdade de Medicina da Universidade Federal de Minas Gerais - UFMG - Belo Horizonte (MG), Brasil; Chefe do Serviço de Cirurgia do Quadril do Hospital Ortopédico e do Hospital Belo Horizonte - Belo Horizonte (MG), Brasil.

2. Ortopedista do Hospital Belo Horizonte e do Hospital Ortopédico - Belo Horizonte (MG), Brasil.

Endereço para correspondência: Rua Prof. Otávio Coelho Magalhães, 111, Mangabeiras - 30210-300 - Belo Horizonte (MG), Brasil. Tel.: (31) 32891211; fax: (31) 3227-0666. E-mail: sfdrumond@hotmail.com

Recebido em 26/6/06. Aprovado para publicação em 27/7/07.

Copyright RBO2007 to (dois quadris), infecção (um quadril) e afrouxamento acetabular (um quadril). Todos os resultados insatisfatórios ocorreram no grupo de afrouxamento asséptico, mas esse achado não foi estatisticamente significante $(p=0,569)$. A restauração do estoque ósseo (avaliação radiográfica) foi encontrada de modo consistente na maioria dos casos, sem correlação com a idade dos pacientes $(p=0,852)$. Os resultados clínicos não tiveram também relação com a idade dos pacientes $(\mathrm{p}=\mathbf{0 , 6 3 6 )}$. Conclusão: $O$ procedimento da revisão femoral com a prótese de Wagner produz resultados clínicos e radiográficos satisfatórios e, de modo consistente, restaura o estoque ósseo do fêmur.

Descritores - Fraturas do quadril; Artroplastia de quadril/métodos; Prótese de quadril; Falha de prótese

\section{ABSTRACT}

Objective: To evaluate 49 hips in 48 patients submitted to revision total hip arthroplasty using Wagner stem. Methods: From April 1999 to January 2005, 49 hips were treated in patients with femoral loosening (39 hips) or periprosthetic fracture of the femur (10 hips) with revision arthroplasty using the Wagner prosthesis. Mean follow-up lasted 35 months and mean age was 63.4 years. Revisions of the femoral component were performed in 49 hips, with concomitant acetabular component revision in 36 hips. Results: Results evaluation according to the D'AubignèPostel-Charnley index presented a statistically significant improvement in the post-operative period in comparison to the pre-operative period $(p<0.001)$. The most important problems seen were the high rate of dislocations (three hips) 
and dislocations associated to the deepening of the stem (two hips). The four unsatisfactory results were due to loosening (two hips), infection (one hip), and acetabular loosening (one hip). All of the unsatisfactory results occurred in the group of aseptic loosening, but this finding was not statistically significant $(p=0.569)$. Restoration of bone stock (radiographic evaluation) was seen consistently in most cases, without correlation with patient age $(p=0.852)$. Likewise, clinical results were not related to patient ages ( $p=$ 0.636). Conclusion: The procedure of femoral revision with Wagner prosthesis yields clinical and radiographic satisfactory results and consistently restores femoral bone stock.

Keywords - Hip fractures; Arthroplasty, replacement, hip/methods; Hip prosthesis; Prosthesis failure

\section{INTRODUÇÃO}

A reconstrução femoral nos afrouxamentos assépticos e fraturas periprotéticas é um problema complexo devido à perda do estoque ósseo do fêmur ${ }^{(1-2)}$.

Para obter com sucesso a reconstrução a longo prazo, é necessário um implante estável, que mantenha ou restaure o estoque ósseo ${ }^{(3)}$.

As opções de tratamento incluem hastes longas, cimentadas ou não, com fixação proximal ou distal, associadas ou não a enxerto ósseo impactado ou estruturado ${ }^{(4-5)}$.

O objetivo do presente estudo é avaliar os resultados clínicos e radiográficos do tratamento de fraturas periprotéticas do fêmur e afrouxamentos femorais, em artroplastias de quadril, com a prótese de Wagner ${ }^{(6)}$.

\section{MÉTODOS}

De abril de 1999 a janeiro de 2005, foram operados, no Serviço de Ortopedia dos Hospitais Belo Horizonte e Ortopédico de Belo Horizonte, 52 pacientes (53 quadris), submetidos a revisão de artroplastia total. Foram utilizadas próteses de Wagner em todas as revisões femorais, tendo sido feitas 36 revisões acetabulares concomitantes.

Foram excluídos da avaliação quatro pacientes (quatro quadris) falecidos de causas não relacionadas à operação na época deste trabalho.

Dos 48 pacientes (49 quadris) estudados, 26 eram do sexo masculino e 23 do feminino (gráfico 1). O lado predominante foi o esquerdo (27 quadris) e o direito apresentou 22 quadris (gráfico 2). A média de idade dos pacientes na época da ope- ração foi de 63,4 anos. O paciente mais jovem tinha 41 anos e o mais idoso, 83 anos (tabela 1). O gráfico 3 mostra a divisão dos quadris em duas faixas etárias: até 59 anos e de 60 ou mais anos. Os diagnósticos prévios às artroplastias primárias mais freqüentes foram: artrose primária (25 quadris), seqüela de fratura (oito quadris), artroses secundárias (sete quadris) e outros diagnósticos (nove quadris) (gráfico 4).

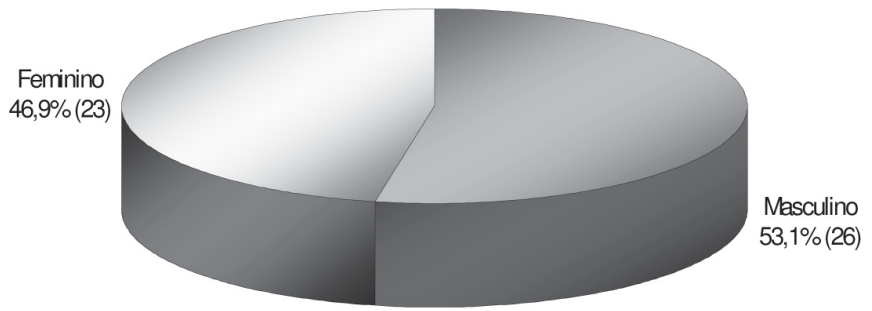

Gráfico 1 - Caracterização dos pacientes quanto ao sexo Fonte: HBH e HO, 2005.

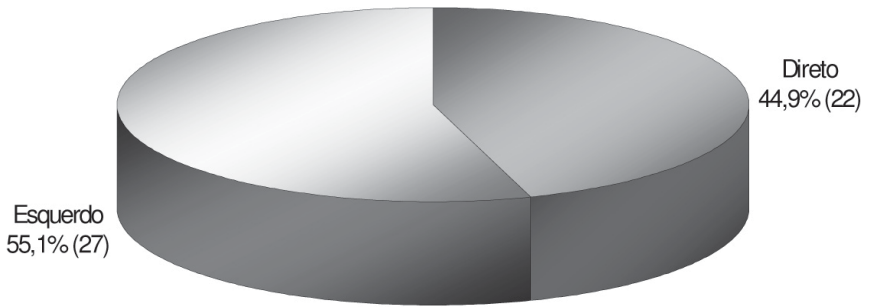

Gráfico 2 - Caracterização dos pacientes quanto ao lado acometido

Fonte: $\mathrm{HBH}$ e HO, 2005.

TABELA 1

Análise descritiva da idade dos pacientes

\begin{tabular}{lcccccc}
\hline Variável & $\begin{array}{c}\text { Número } \\
\text { de } \\
\text { quadris }\end{array}$ & \multicolumn{4}{c}{ Medidas descritivas } \\
\cline { 3 - 6 } & Mínimo & Máximo Mediana & Média & $\begin{array}{c}\text { d.p. } \\
\text { (desvio } \\
\text { padrão) }\end{array}$ \\
\hline $\begin{array}{l}\text { Idade } \\
\text { (anos) }\end{array}$ & 49 & 41,0 & 83,0 & 65,0 & 63,4 & 13,2 \\
\hline
\end{tabular}

Fonte: $\mathrm{HBH}$ e HO, 2005.

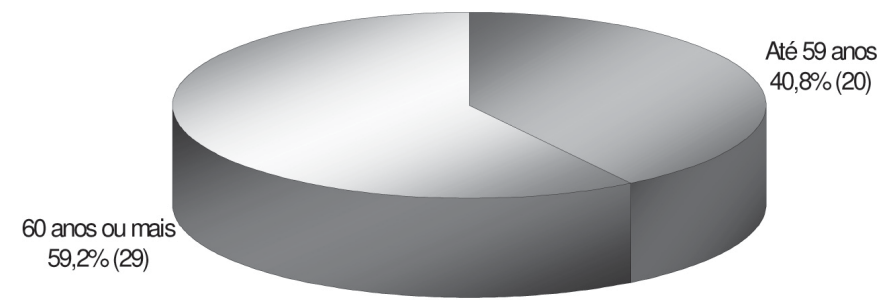

Gráfico 3 - Caracterização dos pacientes quanto à faixa etária Fonte: $\mathrm{HBH}$ e HO, 2005. 


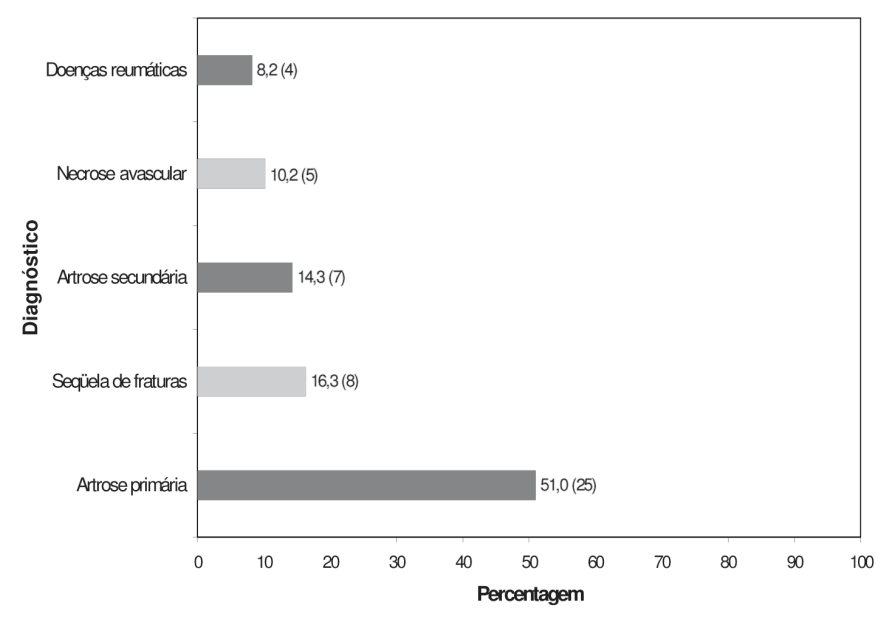

Gráfico 4 - Caracterização dos pacientes quanto ao diagnóstico Fonte: $\mathrm{HBH}$ e HO, 2005.

Os pacientes foram anteriormente submetidos a uma ou mais artroplastias antes da presente cirurgia de revisão. A maioria foi submetida a apenas uma operação anterior $(51 \%)$ e cinco pacientes, a mais de três operações (gráfico 5).

As indicações para revisões femorais foram: afrouxamento asséptico em 39 quadris e fraturas periprotéticas em 10 quadris.

Os defeitos ósseos observados nos afrouxamentos femorais foram classificados segundo a classificação da AAOS em tipo 2 ou cavitários (28 quadris) e tipo 3 ou segmentares e cavitários combinados (11 quadris) ${ }^{(7)}$.

Todas as fraturas periprotéticas foram classificadas como defeitos ósseos tipo 6, segundo a $\operatorname{AAOS}^{(7)}$ (figura 1).

Um dos pacientes com defeito combinado cavitário e segmentar apresentava também associado defeito tipo 4 (deformidade).

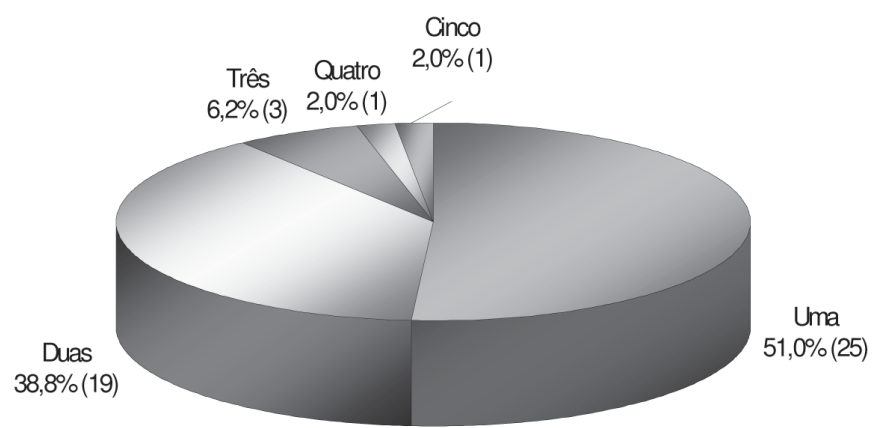

Gráfico 5A - Caracterização dos pacientes quanto ao número de cirurgias anteriores

Fonte: $\mathrm{HBH}$ e $\mathrm{HO}, 2005$.

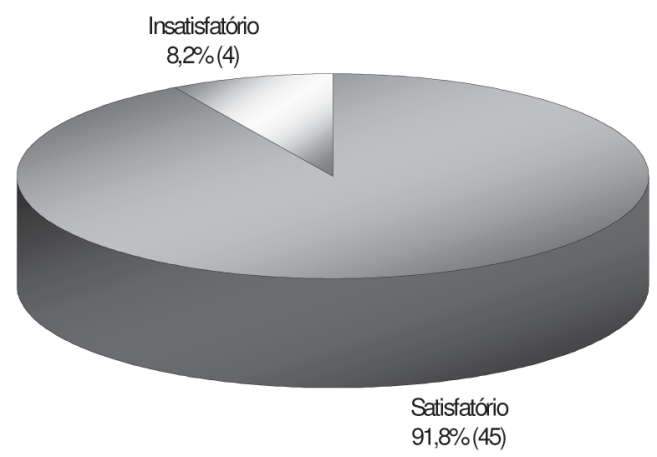

Gráfico 5B - Caracterização dos pacientes quanto ao resultado da avaliação clínica no pós-operatório (soma dos escores dor, marcha e mobilidade)

Fonte: $\mathrm{HBH}$ e HO, 2005.

As fraturas periprotéticas foram classificadas como tipos B2 (três casos) e B3 (sete casos), segundo a classificação de Vancouver $^{(8-9)}$ (figura 2).

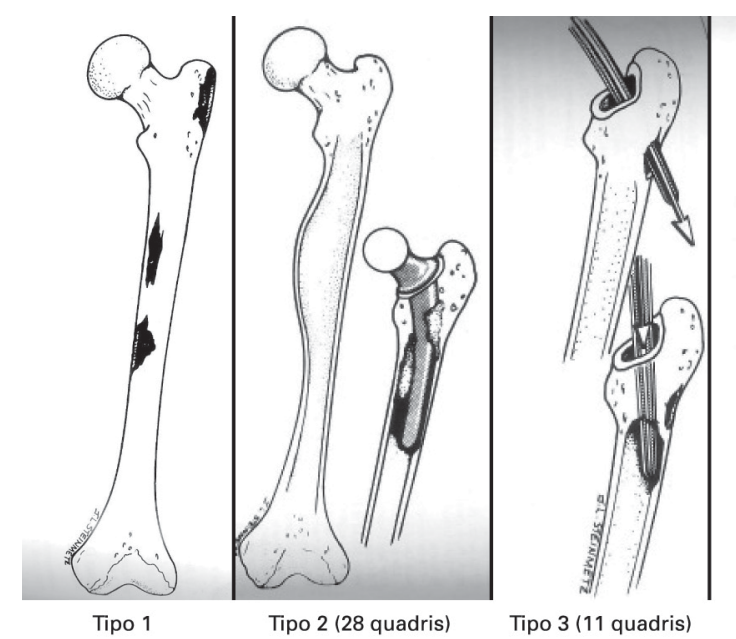

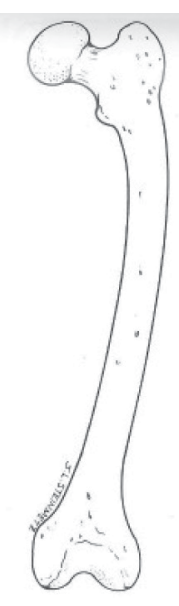

Tipo 4

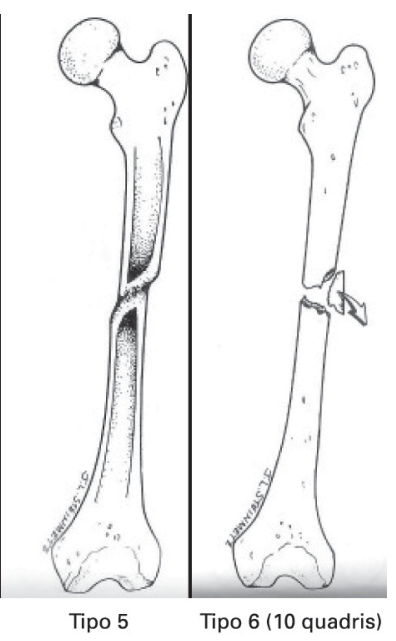

Tipo 5 Tipo 6 (10 quadris)

Figura 1 - Classificação de defeitos femorais da AAOS(7), segundo D'Antonio $\mathrm{J}$ et al 


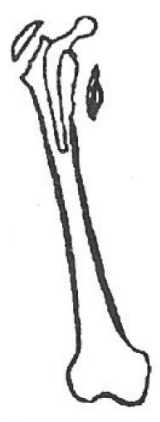

Tipo A
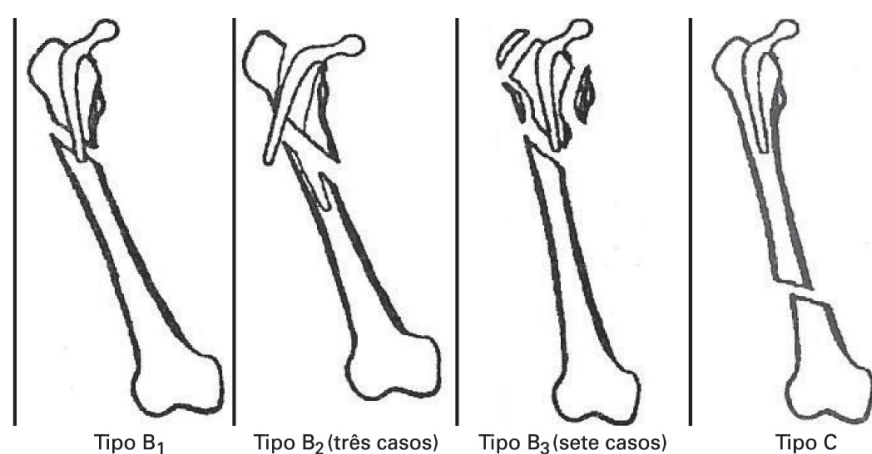

Figura 2 - Classificação de fraturas periprotéticas de Vancouver ${ }^{(8-9)}$, segundo Masri BA, Meek RM e Duncan CP

As fraturas do tipo B situam-se em torno da prótese. As do tipo B2 são aquelas nas quais a haste está instável, mas com bom estoque ósseo. As do tipo B3 apresentam a haste instável e estoque ósseo inadequado.

Os pacientes foram seguidos pelo tempo médio de 35 meses. O seguimento mínimo foi de 12 meses e o máximo, de 76 meses.

Os pacientes foram classificados no pré-operatório pelo sistema de D'Aubignè e Postel ${ }^{(10)}$ modificado por Charnley e Cupic ${ }^{(11)}$, segundo os critérios de dor, qualidade de marcha e mobilidade.

Foi realizada também avaliação da restauração óssea após a colocação da prótese de Wagner pelo critério de Isacson et $a l$, que a classifica em quatro grupos distintos: 1) Sem formação óssea ou com reabsorção óssea; ausência de consolidação da fratura; 2) Formação óssea limitada; consolidação da fratura; 3) Formação moderada de osso com osso esponjoso envolvendo a haste; consolidação da fratura; 4) Extensas áreas de formação óssea com osso cortical em torno da haste; consolidação da fratura com calo ósseo exuberante(12).

Esse método de avaliação é subjetivo, porém permite avaliação adequada da formação óssea obtida no pós-operatório.

\section{Características da haste de Wagner}

A haste de revisão de Wagner é fabricada com uma liga de titânio, alumínio e nióbio e é autobloqueante, designada para uso sem cimento. Apresenta aspecto cônico com ângulo de $2^{\circ}$ de proximal para distal e oito aletas para ancoragem no canal medular e estabilização rotacional. Sua superfície é revestida de titânio jateado rugoso, que possibilita crescimento ósseo e fixação biológica.

Um novo modelo com desvio lateral (off-set) aumentado, perfurações metafisárias para ancoragem de partes moles e novo sistema de introdução foi apresentado recentemente.
A haste tradicional tem ângulo centro-cervicodiafisário (CCD) de $145^{\circ}$ e off-set de $36 \mathrm{~mm}$ (figura 3 ).

A nova haste tem CCD de $135^{\circ}$ com off-set que varia de 42 a $46 \mathrm{~mm}$, dependendo do diâmetro da prótese (figura 4).

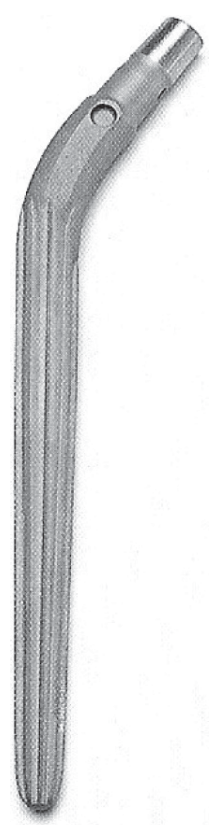

Figura 3 - Prótese de Wagner tradicional com ângulo CCD de $145^{\circ}$ e off-set de $36 \mathrm{~mm}$

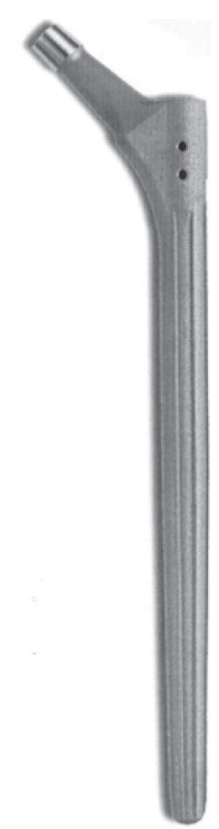

Figura 4 - Nova haste lateralizada, com orifícios proximais para fixação, ângulo CCD de $135^{\circ}$ e off-set de $42 \mathrm{~mm}$ a $46 \mathrm{~mm}$
Nos pacientes estudados, foram usadas 29 próteses tradicionais e 20 próteses de nova geração.

As hastes de Wagner estão disponíveis em tamanhos de $190 \mathrm{~mm}, 225 \mathrm{~mm}, 265 \mathrm{~mm}$ e $305 \mathrm{~mm}$. Sua espessura varia de 14 a $25 \mathrm{~mm}$. 


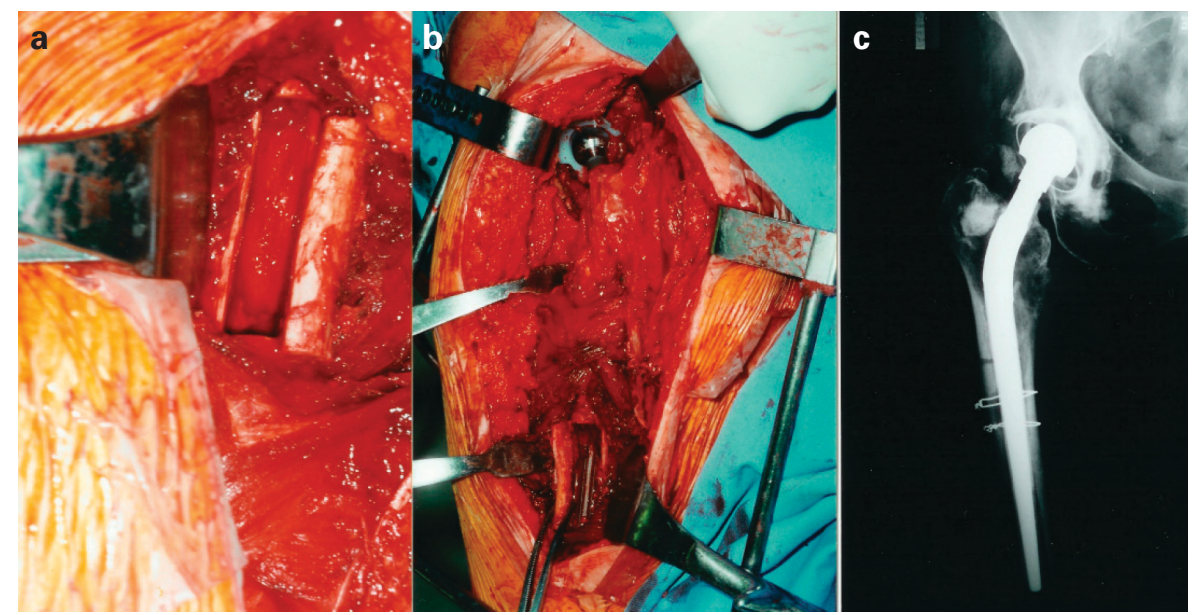

Figura 5 - a) Acesso com janela pediculada para retirada de prótese afrouxada e do cimento ósseo; b) Prótese de Wagner colocada; c) Aspecto radiográfico após síntese com arames de aço.

\section{Técnica cirúrgica}

$\mathrm{O}$ acesso utilizado na maioria dos quadris (36 casos) foi o do tipo Hardinge ${ }^{(13)}$ com janela pediculada ${ }^{(14)}$ (figura 5). O acesso com janela não pediculada foi utilizado em três dos primeiros casos.

Nos casos de fraturas periprotéticas (10 casos) foi utilizado o acesso através do defeito. O acesso tipo Wagner transfemoral citado por Aribindi et $a l^{(15)}$ foi usado somente em um caso.

Em todos os casos foi utilizado antibiótico venoso por tempo mínimo de 48 horas, iniciado na indução anestésica. Foi realizada a prevenção medicamentosa do tromboembolismo com heparina de baixo peso molecular em todos os pacientes, iniciando no dia ou no dia seguinte ao da operação.

No pós-operatório o paciente foi mantido sem apoio por três semanas, acamado, em cadeira de rodas ou em bengalas canadenses. $\mathrm{O}$ apoio parcial foi estimulado a partir de três semanas e progressivamente liberado, sendo o apoio irrestrito permitido aproximadamente aos três meses.

\section{Análise estatística}

As comparações entre as medidas do pré e pós-operatório em relação aos escores que avaliam dor, marcha, mobilidade e escore geral foram realizadas utilizando o teste de Wilcoxon*.

As comparações entre os grupos fratura periprotética e afrouxamento e entre os pacientes com idade até 59 anos e aqueles com 60 anos ou mais no que se refere ao resultado da restauração óssea e ao resultado da avaliação subjetiva foram realizadas utilizando-se o teste exato de Fisher** (teste similar ao $\left.\chi^{2}\right)$.

Com o objetivo de comparar os grupos fratura periprotética e afrouxamento quanto à média das idades dos pacientes, foi utilizado o teste $t$ de Student ${ }^{* * *}$ para amostras independentes.

Os resultados foram considerados significativos quando apresentaram probabilidade de significância inferior a 5\% (p $<0,05$ ) tendo, portanto, pelo menos $95 \%$ de confiança nas conclusões apresentadas.

\section{RESULTADOS}

A avaliação pós-operatória pelo sistema de D'Aubignè e Postel $^{(10)}$, modificado por Charnley e Cupic ${ }^{(11)}$, foi feita calculando-se o somatório dos achados referentes a dor, marcha e amplitude de movimento articular. Os valores de 16 a 18 caracterizam resultados satisfatórios e os valores de 15 e abaixo representam resultados insatisfatórios. Foram 45 resultados satisfatórios $(91,8 \%)$ e quatro insatisfatórios $(8,2 \%)$, de acordo com o critério clínico de avaliação (gráfico 5). Esse resultado foi idêntico ao da avaliação subjetiva dos pacientes.

A avaliação dos resultados pelo critério de D'Aubignè e Postel $^{(10)}$, modificado por Charnley e Cupic ${ }^{(11)}$, mostrou diferença estatisticamente significante $(\mathrm{p}<0,05)$ entre as medi-

\footnotetext{
* Conover WJ. Practical nonparametric statistics. New York: John Wiley \& Sons, 1980;493-9.

** Everitt BS. The analysis of contingency table. London: Chapman and Hall, 1989;128-35.

*** Johnson R, Bhattacharyya G. Statistics principles and methods. New York: John Wiley \& Sons, 1986;578-89. 
das pré e pós-operatórias no que tange aos escores de dor, marcha e mobilidade.

O gráfico 6 mostra o aspecto pré-operatório e o gráfico 7, o aspecto pós-operatório com a melhora clínica.

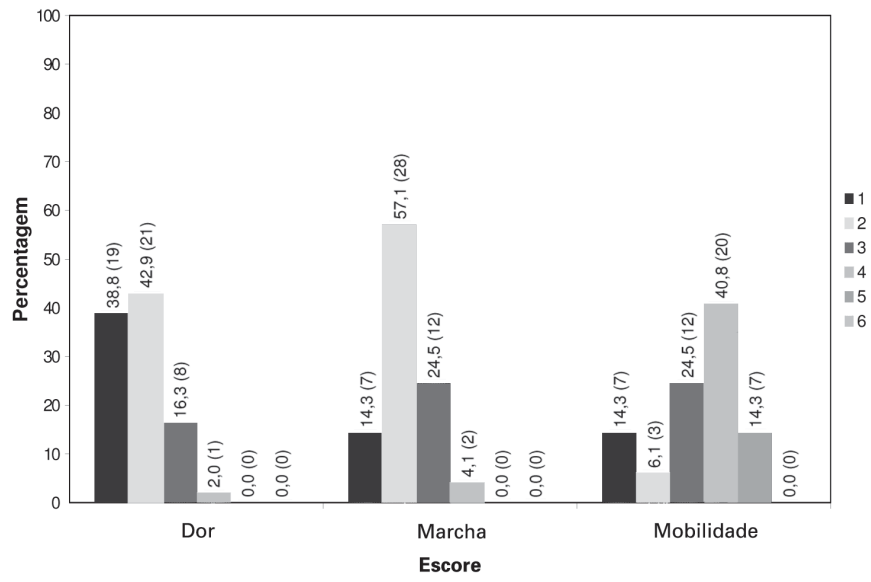

Gráfico 6 - Caracterização dos pacientes quanto aos escores que avaliam a dor, a marcha e a mobilidade no pré-operatório Fonte: HBH e HO, 2005.

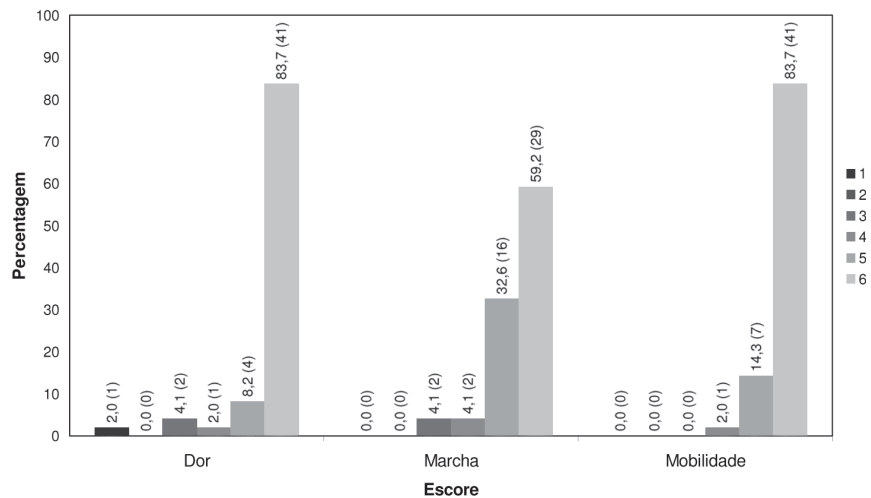

Gráfico 7 - Caracterização dos pacientes quanto aos escores que avaliam a dor, a marcha e a mobilidade no pós-operatório Fonte: $\mathrm{HBH}$ e HO, 2005.

As fraturas recentes foram em número de sete e as fraturas envelhecidas (de um a três meses), em número de três. As fraturas recentes foram consideradas como grau 1 nos escores dor, marcha e mobilidade, enquanto as fraturas envelhecidas foram consideradas como grau 2 nesses três escores.

Os gráficos 8, 9 e 10 mostram, respectivamente, a comparação entre os critérios de dor, marcha e mobilidade no pré e no pós-operatório.

Em relação à formação óssea em torno da prótese, houve 27 casos $(55,1 \%)$ com extensa restauração óssea, 15 casos $(30,6 \%)$ com formação óssea moderada e sete casos $(14,3 \%)$ com limitada produção óssea (gráfico 11).

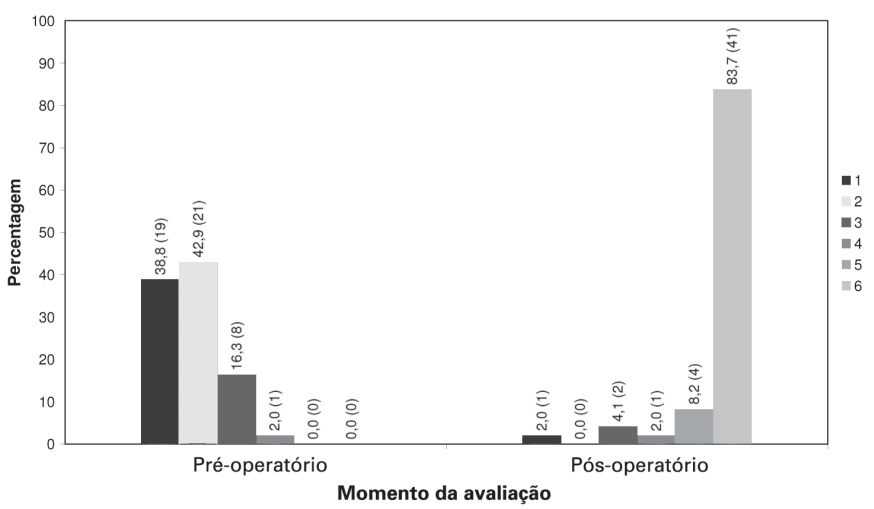

Gráfico 8 - Comparação entre as medidas do pré e do pós-operatório em relação ao escore que avalia a dor Fonte: $\mathrm{HBH}$ e HO, 2005.

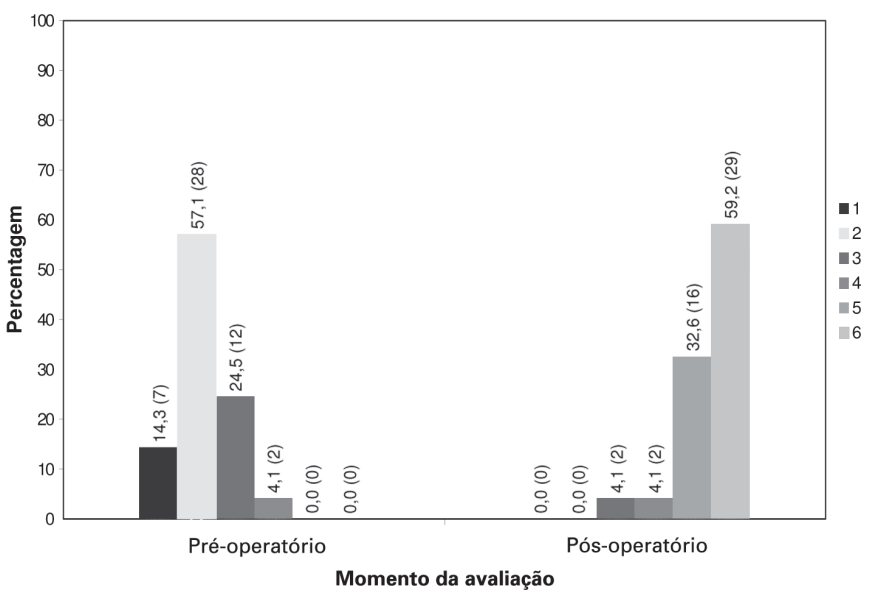

Gráfico 9 - Comparação entre as medidas do pré e do pós-operatório em relação ao escore que avalia a marcha

Fonte: HBH e HO, 2005.

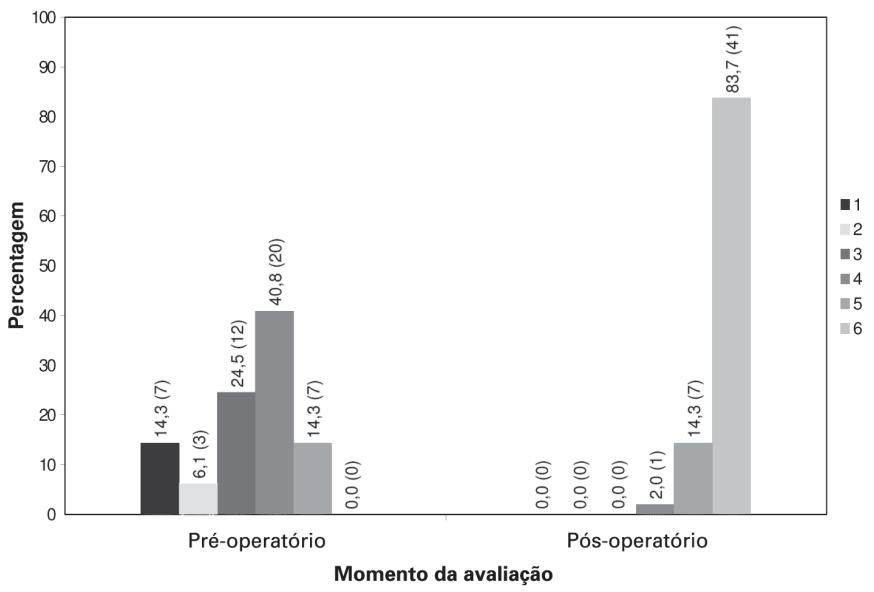

Gráfico 10 - Comparação entre as medidas do pré e do pós-operatório em relação ao escore que avalia a mobilidade Fonte: $\mathrm{HBH}$ e HO, 2005. 


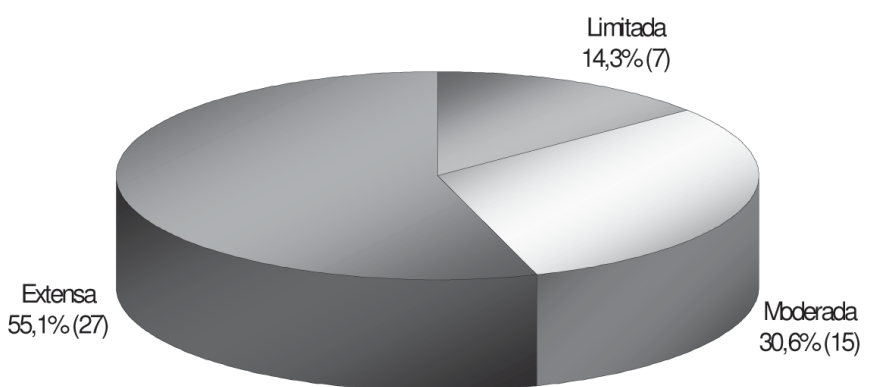

Gráfico 11 - Caracterização dos pacientes quanto à restauração óssea

Fonte: $\mathrm{HBH}$ e $\mathrm{HO}, 2005$.

Além dos resultados globais referentes a pré e pós-operatório já relatados, foram considerados como variáveis para estudo os dois grupos de diagnóstico: fraturas periprotéticas e afrouxamentos assépticos; os dois grupos de idade: até 59 anos e 60 anos ou mais; a qualidade de restauração óssea e os resultados clínicos.

\section{Restauração óssea $x$ grupos afrouxamentos assépticos e fraturas periprotéticas}

A avaliação entre os grupos de afrouxamento asséptico e fraturas periprotéticas em relação à restauração óssea mostra que não existe diferença estatisticamente significante $(p>0,05)$ entre os mesmos. A restauração óssea foi semelhante nos dois grupos, de acordo com os achados de restauração limitada, moderada e extensa (gráfico 12).

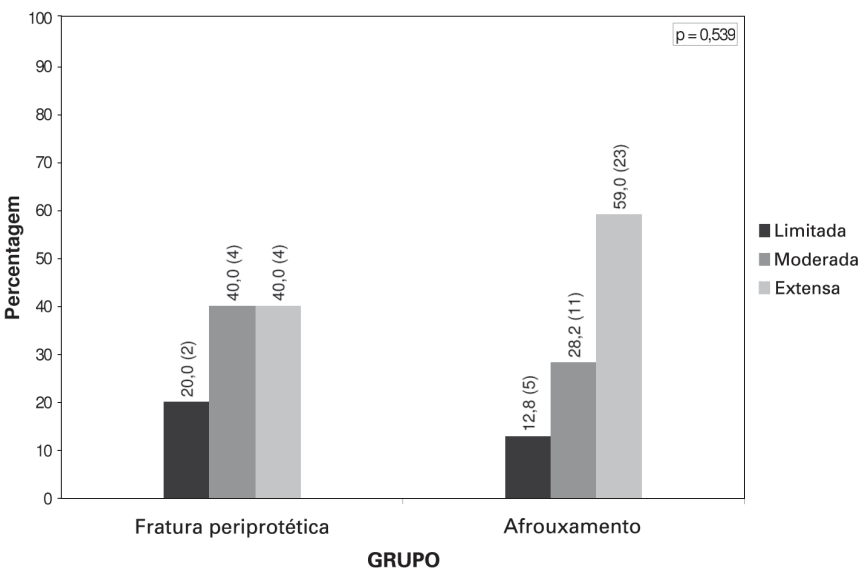

Gráfico 12 - Comparação entre os grupos fratura periprotética e afrouxamento em relação à restauração óssea Fonte: $\mathrm{HBH}$ e $\mathrm{HO}, 2005$.

\section{Restauração óssea $\mathrm{x}$ idade}

Na comparação de grupos de idade até 59 anos e 60 anos ou mais, não houve diferença estatisticamente significante ( $\mathrm{p}$ $>0,05$ ) em relação à formação óssea (gráfico 13).

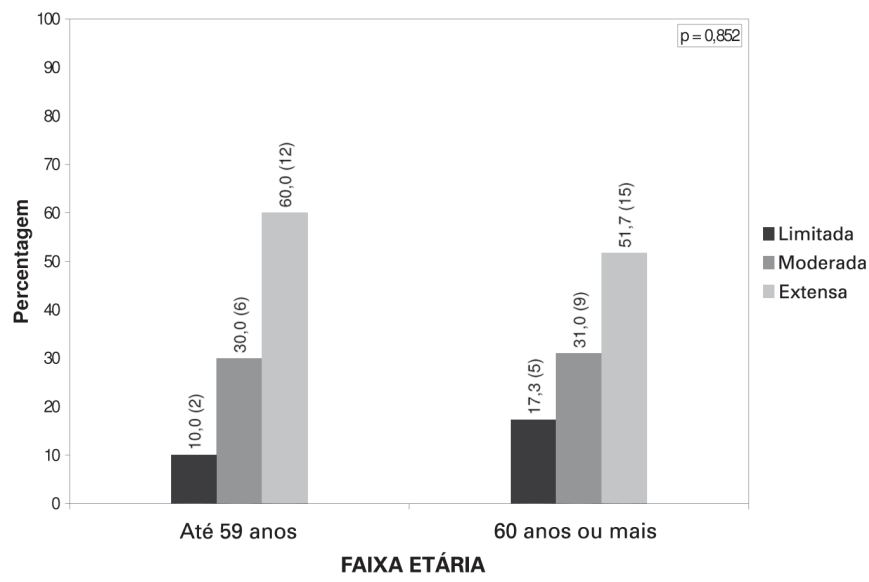

Gráfico 13 - Comparação entre as duas faixas etárias dos pacientes em relação à restauração óssea Fonte: $\mathrm{HBH}$ e $\mathrm{HO}, 2005$.

\section{Resultado clínico $\mathrm{x}$ grupos fraturas periprotéticas $\mathrm{e}$ afrouxamentos}

Os resultados foram satisfatórios em todos os casos de fratura periprotética. Os maus resultados ocorreram no grupo de afrouxamento. Apesar dessa evidência, esses resultados não foram significantes $(\mathrm{p}=0,569)$ (gráfico 14$)$.

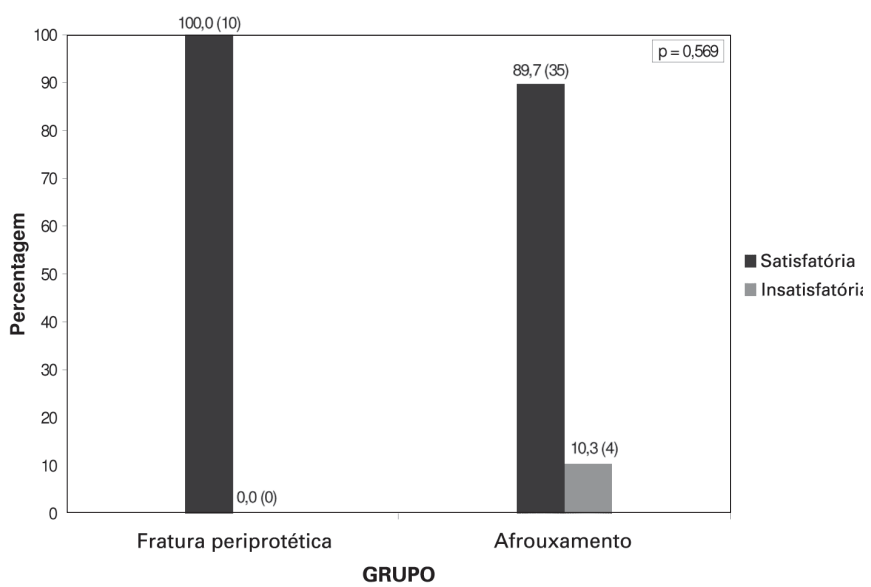

Gráfico 14 - Comparação entre os grupos fratura periprotética e afrouxamento em relação ao resultado da avaliação clínica Fonte: $\mathrm{HBH}$ e HO, 2005

\section{Comparação entre faixas etárias e resultados clínicos}

Os resultados clínicos foram superiores nos pacientes mais jovens $(95 \%)$ do que nos idosos $(89,7 \%)$. Esses dados, no entanto, não foram significantes $(\mathrm{p}=0,636)$ (gráfico 15).

$\mathrm{Na}$ figura 6 observa-se afrouxamento de prótese sem cimento com migração da haste, perfuração da diáfise e luxação do quadril. Realizada revisão com haste de Wagner, com resultado satisfatório e boa restauração óssea. 


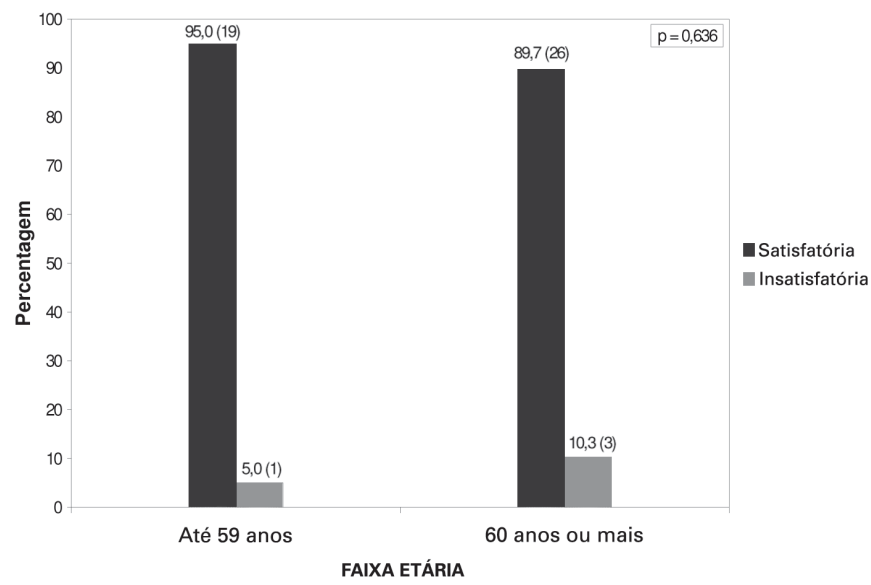

Gráfico 15 - Comparação entre as duas faixas etárias dos pacientes em relação ao resultado da avaliação subjetiva Fonte: $\mathrm{HBH}$ e HO, 2005.
Na figura 7 observa-se fratura periprotética revisada apresentando resultado satisfatório com extensa restauração óssea.

\section{Análise dos maus resultados}

Os quatro maus resultados vieram de: novo afrouxamento asséptico em dois casos, desprendimento da taça em um e infecção com afrouxamento séptico em outro. Na figura 8 observa-se caso de afrouxamento com formação de pedestal.

Na figura 9 vê-se resultado insatisfatório com afrouxamento, migração distal da haste e demarcação entre o osso e a prótese.

A figura 10 retrata resultado insatisfatório devido a afrouxamento da taça acetabular. A haste de Wagner está radiograficamente estável com restauração do estoque ósseo.

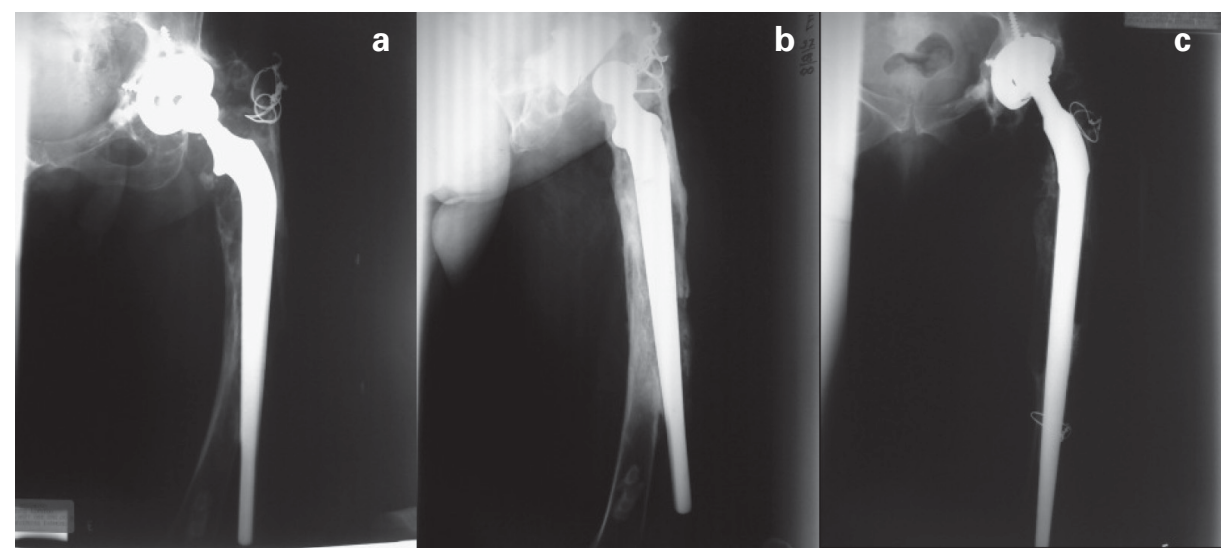

Figuras 6 - a e b) Paciente com defeito segmentar e cavitário combinados associado a angulação moderada; a prótese longa sem cimento encontra-se solta, perfurando a diáfise e com migração distal. c) A prótese de Wagner com osteotomia ao nível da angulação propiciou resultado satisfatório com osteointegração da prótese e restauração do estoque ósseo.

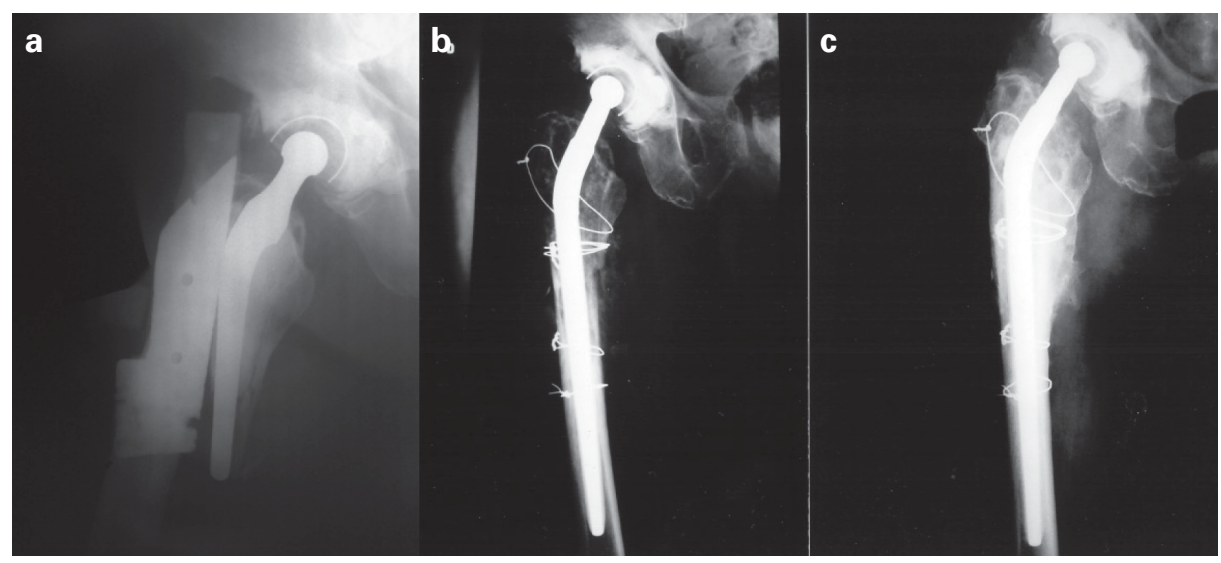

Figura 7 - a) Fratura periprotética após queda de cavalo imobilizada com tala metálica; b) Aspecto radiográfico pós-operatório imediato de revisão femoral; c) Aspecto radiográfico tardio mostrando estabilidade da haste e extensa restauração óssea. 


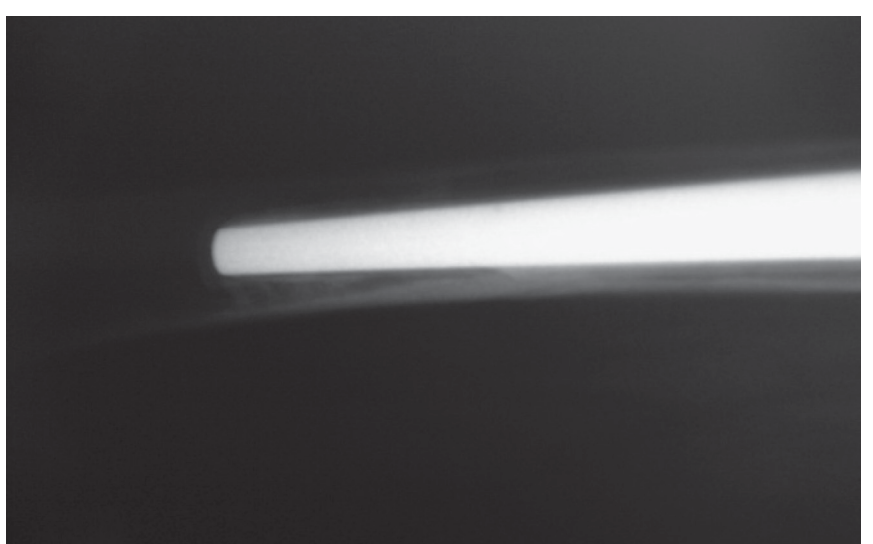

Figura 8 - Resultado insatisfatório com sinais radiográficos de afrouxamento. Reação em torno da prótese e presença de pedestal.

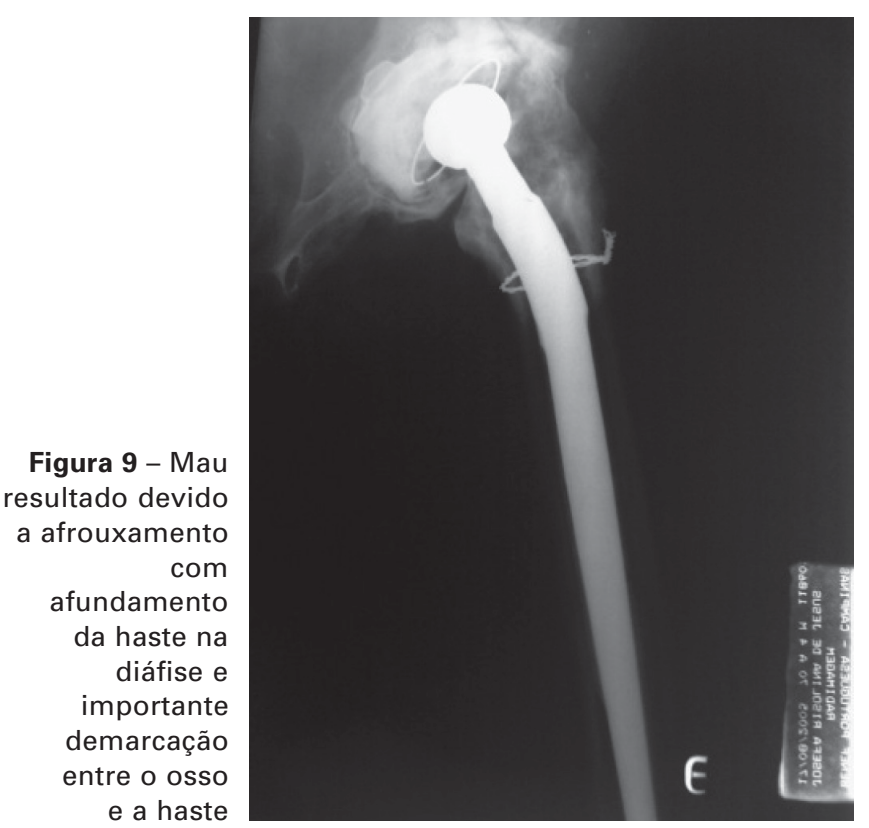

\section{Complicações}

Houve um caso de infecção com afrouxamento séptico da haste. Esse caso foi operado novamente em outro serviço, com tratamento da infecção e troca por outra haste de Wagner. Atualmente, a paciente está em boas condições.

Houve duas luxações relacionadas ao afundamento da haste na diáfise, que foram tratadas com redução cruenta da haste por via distal e bloqueio na extremidade distal com parafuso. Esses dois pacientes apresentaram resultados satisfatórios (figura 11).

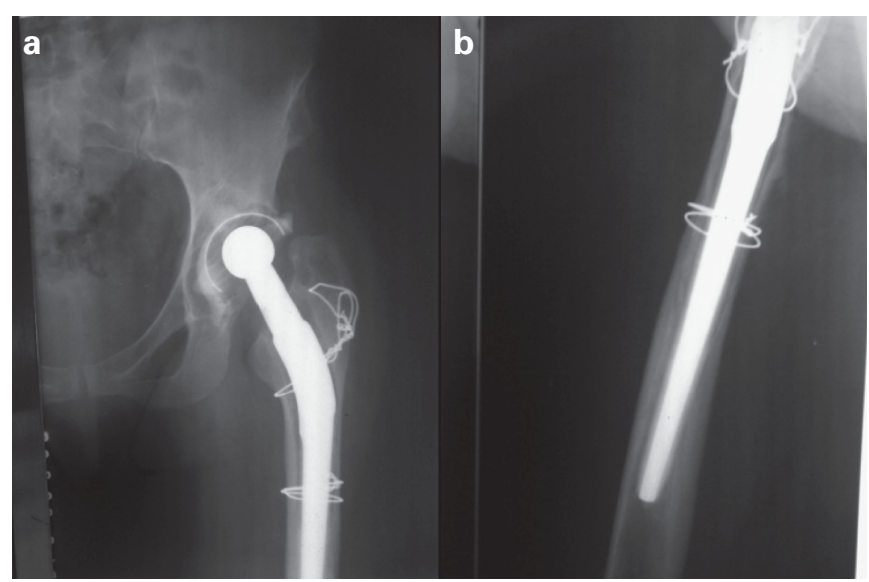

Figura 10 - a) Afrouxamento da taça acetabular com haste estável; b) Detalhe da estabilidade da haste em perfil.

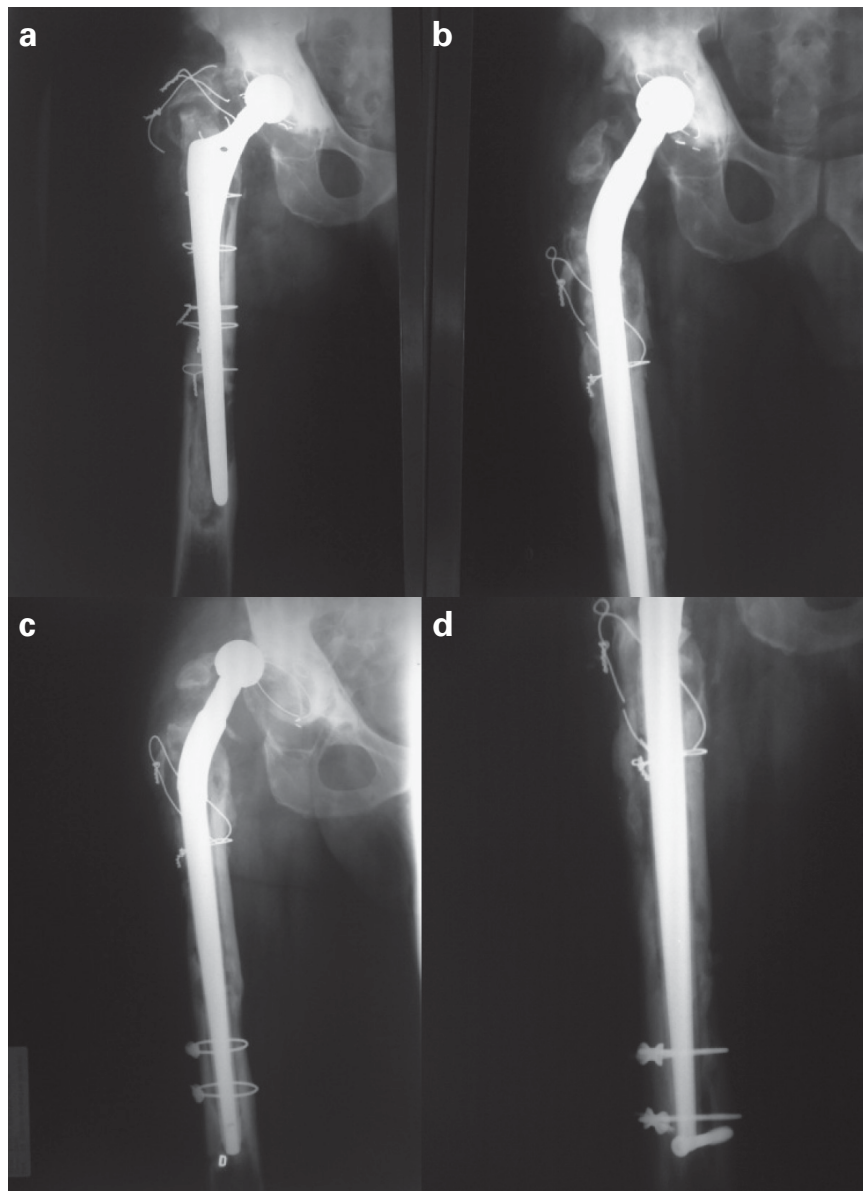

Figura 11 - a) Afrouxamento com haste longa cimentada com defeito cavitário e segmentar; b) Aspecto pós-operatório; c) Afundamento gradativo da haste com luxação; d) Reposicionamento proximal da haste por via distal com redução incruenta da taça e travamento distal da haste com um parafuso. 


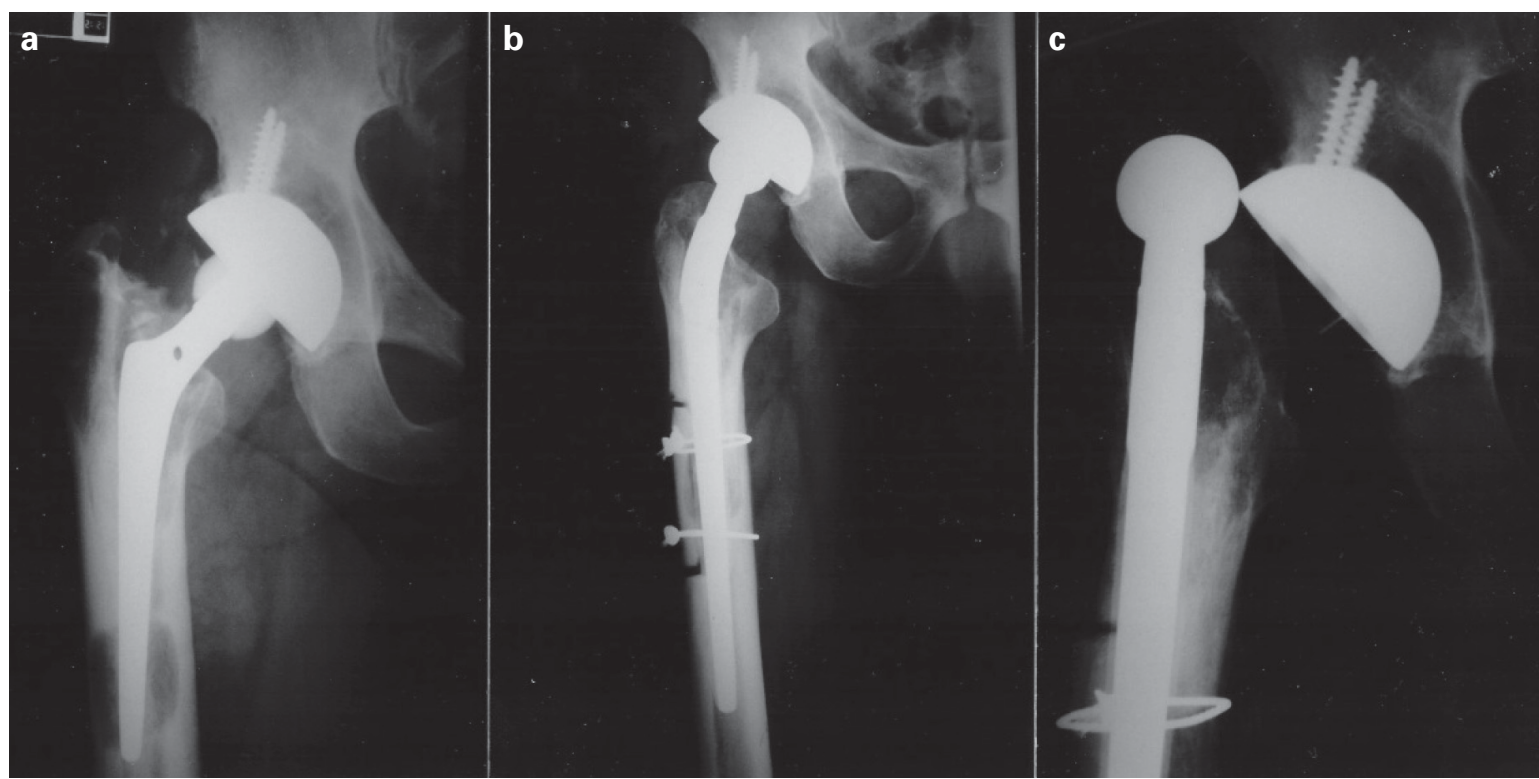

Figura 12 - a) Afrouxamento cavitário do componente femoral (tipo 2); b) Aspecto pós-operatório com colocação de haste de Wagner através de janela femoral, a taça acetabular foi mantida; c) Luxação sem afundamento da haste, submetida posteriormente a redução incruenta sem comprometimento do resultado.

Houve três luxações não relacionadas ao afundamento, que foram tratadas com redução incruenta, sem prejuízo do resultado final (figura 12).

Houve duas fraturas periprotéticas, sendo uma peroperatória e a outra no pós-operatório tardio. Ambas foram fixadas com placas e parafusos associados ao enxerto ósseo autólogo e evoluíram para a cura sem prejuízo do resultado final satisfatório (figura 13).

\section{DISCUSSÃO}

A complexidade da revisão femoral é evidenciada pelo grande número de técnicas e implantes que têm sido desenvolvidos e propostos ${ }^{(16-17)}$. Há técnicas que utilizam hastes longas cimentadas, hastes poróticas não cimentadas, implantes com aletas para fixação distal e implantes para uso com enxerto ósseo esponjoso homólogo impactado ou com enxerto homólogo em bloco ${ }^{(12,16-19)}$.

As revisões cimentadas dos componentes femorais não conseguem atingir a durabilidade das hastes femorais primárias cimentadas. As taxas de falha nesse tipo de reconstrução são muito elevadas ${ }^{(5,20)}$.

As revisões não cimentadas com hastes com revestimento poroso completo dão resultados superiores, porém há sempre a preocupação com ausência de crescimento ósseo em torno da prótese, dor persistente na coxa e stress shielding ${ }^{(17,20)}$.

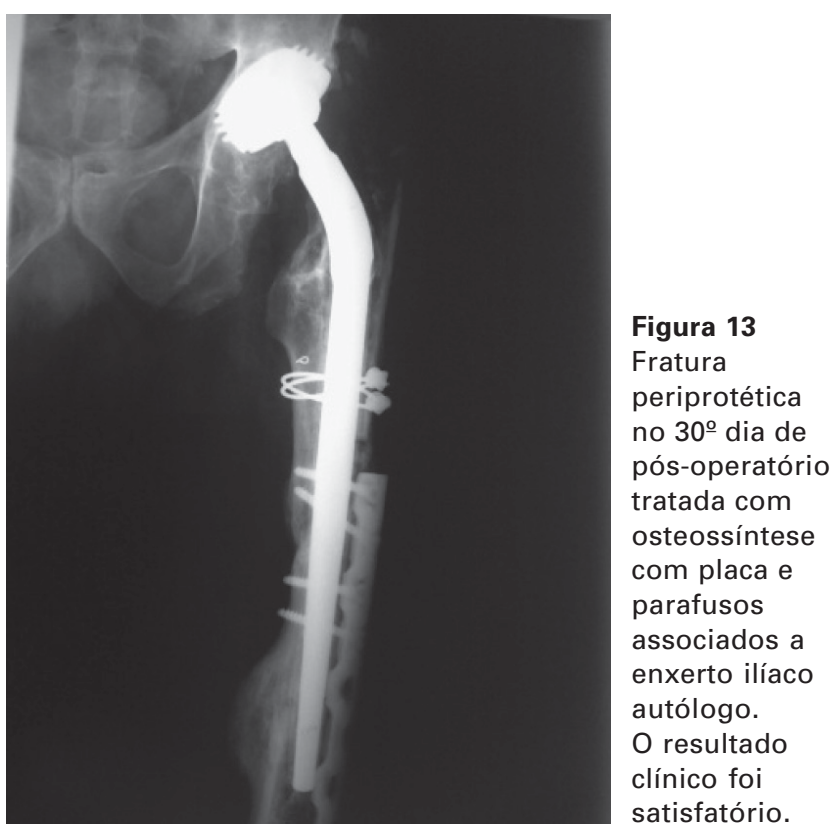

Hungerford e Jones desaconselham o uso de cimento em qualquer revisão devido à deficiência do estoque ósseo ${ }^{(21)}$.

O uso de enxerto ósseo esponjoso homólogo impactado é uma solução para repor o estoque ósseo e apresenta bons resultados quando associado à técnica cimentada ${ }^{(16)}$. Outra op- 
ção é a utilização de enxerto ósseo homólogo estruturado, que repõe o estoque ósseo e propicia bons resultados ${ }^{(18)}$.

No entanto, os procedimentos acima apresentam longo tempo cirúrgico, necessidade de enxerto ósseo homólogo de banco em quantidades suficientes, técnica cirúrgica complexa e pós-operatório trabalhoso ${ }^{(16,18,22)}$.

A prótese de Wagner não resolve o problema do osso deficiente proximal e o afrouxamento ou fratura periprotética por meios convencionais, mas transpõe o defeito ósseo e ancorase distalmente em osso de boa qualidade. Há evidências de que esse tipo de técnica restaura o osso proximal espontaneamente $^{(6,12,19,23)}$.

A revisão femoral com haste de Wagner mostrou resultados satisfatórios em 45 dos 49 quadris $(91,8 \%)$, com falha em apenas quatro quadris $(8,2 \%)$ nos casos por nós avaliados. Foi evidenciada também a restauração óssea extensa em 27 casos $(55,1 \%)$, moderada em $15(30,6 \%)$ e limitada em apenas sete

\section{REFERÊNCIAS}

1. Head WC, Malinin TI, Emerson RH, Mallory TH. Restoration of bone stock in revision surgery of the femur. Int Orthop. 2000;24(1):9-14.

2. Haddad FS, Masri BA, Garbuz DS, Duncan CP. Femoral bone loss in total hip arthroplasty: classification and preoperative planning. Instr Course Lect. 2000;49:83-96.

3. Aribindi R, Barba M, Solomon MI, Arp P, Paprosky W. Bypass fixation. Orthop Clin North Am. 1998;29(2):319-29.

4. Gross AE, Hutchison CR. Proximal femoral allografts for reconstruction of bone stock in revision arthroplasty of the hip. Orthop Clin North Am. 1998;29(2):313-7.

5. Crawford SA, Siney PD, Wroblewski BM. Revision of failed total hip arthroplasty with a proximal femoral modular cemented stem. J Bone Joint Surg Br. 2000;82(5):684-8.

6. Wagner H. Hip prosthesis revision with the non-cemented femoral revision stem - 10 years experience. Med Orthop Tech. 1997;117:138-48.

7. D'Antonio J, McCarthy JC, Bargar WL, Bordon LS, Cappelo WN, Collis DK, et al. Classification of femoral abnormalities in total hip arthroplasty. Clin Orthop Relat Res. 1993;(296):133-9.

8. Masri BA, Meek RM, Duncan CP. Periprosthetic fractures evaluation and treatment. Clin Orthop Relat Res. 2004;(420):80-95.

9. Duncan CP, Masri BA. Fractures of the femur after hip replacement. Instr Course Lect. 1995;44:293-304. Review.

10. D'Aubigne RM, Postel M. Functional results of hip arthroplasty with acrylic prosthesis. J Bone Joint Surg Am. 1954;36-A(3):451-75.

11. Charnley J, Cupic Z. The nine and ten year results of low-friction arthroplasty of the hip. Clin Orthop Relat Res. 1973;(95):9-25.

12. Isacson J, Stark A, Wallensten R. The Wagner revision prosthesis consistently restores femoral bone structure. Int Orthop. 2000;24(3):13942.
(14\%). Esses dados confirmam os da literatura, que mostram restauração óssea de modo consistente na maioria dos casos sem evidência de stress shielding ou dor na coxa ${ }^{(6,12,19)}$.

Os casos avaliados têm seguimento relativamente curto e novas avaliações serão necessárias para situar a real posição da prótese de Wagner nas revisões femorais. As luxações com ou sem afundamento da prótese na diáfise são problemas que poderão ser resolvidos com aprimoramento da técnica cirúrgica, maior experiência dos cirurgiões e evolução no projeto da prótese.

\section{CONCLUSÃO}

O procedimento de revisão femoral com a prótese de Wagner produz resultados clínicos e radiográficos satisfatórios e, de modo consistente, restaura o estoque ósseo da extremidade proximal do fêmur.

13. Hardinge K. The direct lateral approach to the hip. J Bone Joint Surg Br. 1982;64(1):17-9.

14. Kerry RM, Masri BA, Garbuz DS, Duncan CP. The vascularized scaphoid window for access to the femoral canal in revision total hip arthroplasty. Instr Course Lect. 1999;48:9-11.

15. Aribindi R, Paprosky W, Nourbash P, Kronick J, Barba M. Extended proximal femoral osteotomy. Instr Course Lect. 1999;48:19-26. Review.

16. Gie GA, Linder L, Ling RS, Simon JP, Slooff TJ, Timperley AJ. Impacted cancellous allografts and cement for revision total hip arthroplasty. J Bone Joint Surg Br. 1993;75(1):14-21.

17. Bono JV, McCarthy JC, Lee JA, Carangelo RJ, Turner RH. Fixation with a modular stem in revision total hip arthroplasty. Instr Course Lect. 2000; 49:131-9.

18. Pak JH, Paprosky WG, Jablonsky WS, Lawrence JM. Femoral strut allografts in cementless revision total hip arthroplasty. Clin Orthop Relat Res. 1993;(295):172-8.

19. Kolstad K. Revision THR after periprosthetic femoral fractures. An analysis of 23 cases. Acta Orthop Scand. 1994;65(5):505-8.

20. Moreland JR, Bernstein ML. Femoral revision hip arthroplasty with uncemented, porous-coated stems. Clin Orthop Relat Res. 1995;(319): 141-50.

21. Hungerford DS, Jones LC. The rationale of cementless revision of cemented arthroplasty failures. Clin Orthop Relat Res. 1988;(235):12-24.

22. Macdonald SJ, Paprosky WG, Jablonsky WS, Magnus RG. Periprosthetic femoral fractures treated with a long-stem cementless component. J Arthroplasty. 2001;16(3):379-83.

23. Pina Cabral FJ, Rondinelli PC, Silveira SLC. Revisão em artroplastia total do quadril: revisão femoral. Clin Ortop. 2001;2:1201-12. 